\title{
Development of Water Extraction Device from Air Using Condensation Principle
}

\author{
H. S. Nedariya ${ }^{1 *}$, S. R. Pansuriya ${ }^{1}$, J. S. Karena ${ }^{1}$ and H. M. Bhatu ${ }^{2}$ \\ ${ }^{1}$ Students of Agricultural Engineering, School of Engineering, RK University, \\ Rajkot, Gujarat, India \\ ${ }^{2}$ Department of Agricultural Engineering, School of Engineering, RK University Rajkot, India \\ *Corresponding author
}

\section{A B S T R A C T}

\section{Keywords \\ Water From air, \\ Condensation \\ Principle, Moist air, \\ Humidity}

Article Info

Accepted:

07 March 2020

Available Online:

10 April 2020

\begin{abstract}
Water scarcity is not a recent problem. Shortage of drinking water is constant, severe, and wide-spread in the worldwide. Worldwide, people are suffering from lack in adequate fresh drinking water. The amount of fresh water on the earth is only 2.53 percent of the total amount. We can be solved this problem by extraction of water from atmospheric air using condensation principle. It is suitable techniques for remote villages in order to produce clean drinking water. In which a six feet depth pith as made and have one condensation chamber (Water Storage Tank) in it. A $4.5 \mathrm{~W}$ fan is used to suck the air from the atmosphere. This fan is operated by $12 \mathrm{~V}$ solar plates. In this, we can extract about 250 $\mathrm{ml}$ water. If we provide more depth and higher capacity fan than we can extract more amount of water.
\end{abstract}

\section{Introduction}

Water scarcity is not a recent problem. The amount of fresh water on the earth is only 2.53 percent $\left(35\right.$ million $\left.\mathrm{km}^{3}\right)$ of the total amount $\left(1.384\right.$ billion $\left.\mathrm{km}^{3}\right)$. A large fraction of freshwater (24 million $\left.\mathrm{km}^{3}\right)$ is ice and permanent snow in the Antarctic and Arctic regions. The main source of water for human consumption (freshwater lakes and rivers) which about 0.26 percent of the total global fresh water reserves $\left(90,000 \mathrm{~km}^{3}\right)$. Atmospheric air contains about $14,000 \mathrm{~km}^{3}$ of water in vapour form, and hence it can be used as a new and renewable water resource
(3). A Water Aid report in 2016 ranked India, among the worst countries in the world for the number of people without safe water.

Extraction of water form atmospheric air can be accomplished by two different methods. The first method is by cooling moist air to a temperature lower than the air dew point. The second one is by absorbing water vapour from moist air using a solid or liquid desiccant, with subsequent recovery of the extracted water by heating the desiccant and condensing the evaporated water(3). The study was an attempt to make adevice that would be capable of converting atmospheric 
moisture directly into usable and even drinking water. The device uses the principle of latent heat to convert water vapour molecules into water droplets. In many countries like India, there are places which are situated in temperate region; there are deserts, rain forest areas and even flooded areas where atmospheric humidity is eminent (4).

A device that relies on simple condensation promises to collect clean water from the atmosphere without an external power source, greenhouse gas emissions, or adverse environmental impacts. Device could potentially run forever, gifting generations of people with access to 'liquid gold' in areas of the world where a harsh climate or lack of infrastructure make access to clean drinking water a major problem.

\section{Materials and Methods}

The study was carried out at College campus, School of Engineering, RK University, Rajkot Gujarat. The latitude and longitude of the location are $22.3039^{\circ} \mathrm{N}$ and $70.8022^{\circ} \mathrm{E}$ respectively. A $4.5 \mathrm{Watt}$ fan was used to suck the air from the atmosphere and drive it to the condensation chamber through the PVC pipe. The fan has 3 blades and each blade placed at the angle of $45^{\circ}$ For continued operation of the fan, solar plate of $12 \mathrm{~V}$ and 0.9 Ampere was used.

The clay water pot was used for the storage of extracted water. The level of extracted water into the storage tank was determined by water level indicator. The depth of pit for condensation was around 6 feet, so as to produce temperature difference. The air is sucked by fan and converted into the small fine droplets of water and that droplets are collected into the condensation chamber. The water can be lifted from the condensation chamber with the help of a hand pump. Below given sketch shows the design of device with their Dimensions.

\section{Results and Discussion}

The experiment was carried out in September 2017. During this, temperature of air, temperature of soil, relative humidity and Wind Speed was measured twice in a day at morning and evening. As per the below given parameters the on an average water obtain is $250 \mathrm{ml}$ per 24 hours. The measured parameters are in table 1 .

Some problems were faced during the experiment. Digging was difficult because of Hard Rocks. The depth of pit was 6 feet, it is not sufficient to get more temperature difference (Fig. 1).

Table.1

\begin{tabular}{|l|c|}
\hline Average Temperature of air (Morning) $\left({ }^{\circ} \mathrm{C}\right)$ & $\mathbf{2 6 . 7 3}^{\circ} \mathrm{C}$ \\
\hline Average Temperature of Soil (Morning) $\left({ }^{\circ} \mathbf{C}\right)$ & $21.9^{\circ} \mathrm{C}$ \\
\hline Average Temperature of air (Evening) $\left({ }^{\circ} \mathrm{C}\right)$ & $28.38^{\circ} \mathrm{C}$ \\
\hline Average Temperature of Soil (Evening) $\left({ }^{\circ} \mathbf{C}\right)$ & $25.23^{\circ} \mathrm{C}$ \\
\hline Average Relative Humidity (Morning) $(\boldsymbol{\%})$ & $43.32 \%$ \\
\hline Average Relative Humidity (Evening) $(\boldsymbol{\%})$ & $37.65 \%$ \\
\hline Average Wind Speed (Morning) $(\mathbf{m} / \mathbf{s})$ & $0.89 \mathrm{~m} / \mathrm{s}$ \\
\hline Average Wind Speed (Evening) $(\mathbf{m} / \mathbf{s})$ & $0.52 \mathrm{~m} / \mathrm{s}$ \\
\hline
\end{tabular}


Fig.1 Diagram of device

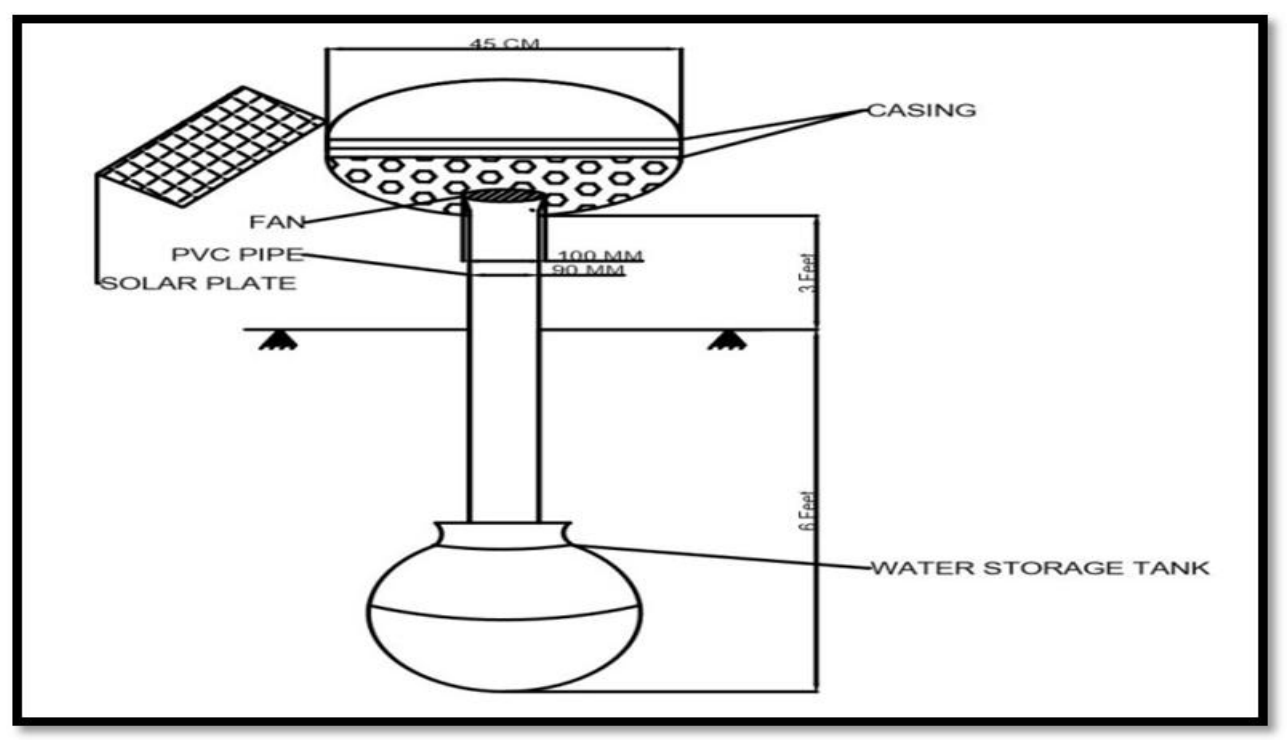

The Temperature difference between soil and the atmosphere was about 3-4 degree and the relative humidity is also less. If we provide more depth and higher capacity fan than we can extract more amount of water. A proofof-concept of the device was tested in 2014 with good results, 2.3 liters of pure water per day in a relatively humid climate. Proof-ofconcept field tests in India extracted an average of 1.75 liters of water per day using a 9 Sq. Meter surface (1).

In conclusion for the extraction of water the soil formations and type of soil, depth of the pit, climate condition and size of fan are the major responsible factor to produce the more water. To get more amount of water the relative humidity should be more. The storage tank should be made up of metal for the ease of collection of extracted water instead of clay. The humidity of a region must remain above $50 \%$ for proper functioning of the device. So we expect that the water output may increase if the device is tested in coastal areas where the humidity is high (2).

\section{References}

1. Anonymous. 2016. VICI Labs Water Seer ${ }^{\mathrm{TM}}$ Collider Competition available at:www.scet.berkeley.edu/wpcontent/uploads/VICI-Labs-Collider ProjectSubmission.pdf.

2. Dash A. and Mohapatra A. 2015. Atmospheric water generated: To meet the drinking water requirements of a household in coastal regions of India. Thesis (unpublished) Department of Mechanical Engineering National Institute of Technology, Rourkela.

3. Golechha T., Lonkar A., Tayde S., Salikh S., Pawar D. 2016. A Technical Review on Atmospheric Water Extraction. International Journal of Research in Advent Technology (IJRAT) (E-ISSN: 2321-9637) In: National Conference "CONVERGENCE 2016", $06^{\text {th }}-07^{\text {th }}$ April 2016.

4. Gupta R., Gupta J., Gupta A., Mahadik U. 2016. Water through Air using Peltier Elements. International Journal of Science Technology \& Engineering Vol. $2(9)$. 


\section{How to cite this article:}

Nedariya, H. S., S. R. Pansuriya, J. S. Karena and Bhatu, H. M. 2020. Development of Water Extraction Device from Air Using Condensation Principle. Int.J.Curr.Microbiol.App.Sci. 9(04): 486-489. doi: https://doi.org/10.20546/ijcmas.2020.904.057 